\title{
Creation of Artistic Conception in Indoor Environment Design
}

\author{
Liu Guangzhe*, Tang Fan \\ Heihe University, Heihe, Heilongjiang 164300
}

Keywords: Indoor environment; Design; Artistic conception; Creation.

\begin{abstract}
This paper explores how to create the artistic conception of interior space from the angle of psychology, colour, light, space form, interior furniture, interior greening, interior decoration and water environment. That is to say, the aesthetic value of indoor environment depends not only on its "own appearance", but also on its "association generated by human beings". That is to say, as the embodiment of aesthetic value, the indoor environment should not only have substantive significance, but also connotative significance.
\end{abstract}

\section{Introduction}

Every good interior design is not pursuing a spiritual charm, that is, the creation of "artistic conception". "Artistic conception" is the soul and essence of interior design. It is a high-level manifestation of interior design. Then, what is the "artistic conception"? "Artistic conception" is the realm pursued by Chinese traditional art. There is an old saying, "Every painting and calligraphy should watch its rhyme". The "rhyme" here refers to spirit and temperament, which makes the works contain the depth of meaning but not the depth of the pen. Applying this aesthetic theory to interior design is to create interior design with higher aesthetic value and rich connotation. Therefore, in the indoor environment space with higher spiritual function requirements, we should pursue a charm beyond space. And this charm is an indescribable artistic charm -- "artistic conception" produced by the sympathy between things and feelings in the interior space. In the interior space, people and life are the purpose and the main body. The indoor space environment built for the needs of people's life is means and object. As the subject, people accept the surroundings as objects from the sensory perception cells, such as color, texture, shape, lines and so on. These factors first act on the human sensory cells, and then they are transmitted to the relevant parts of the human body through the nervous system, causing extremely complex emotional reactions. In other words, the emotional activities in the aesthetic process are the result of the interaction between the physical nature of the environment and the spiritual activities of human beings.

\section{The Use of Colour in Indoor Environment}

Colours give people a strong feeling. Different colors and different combinations of colors will 
give people different feelings. When designing interior environment, we must consider the space effect of interior colour and the emotional effect of color.

\subsection{Colours Can Arouse People's Feelings}

We should use their emotional effects skillfully in design. (1) colour feels cool and warm. Some colors make people feel warm, such as red, reminiscent of fire, orange and yellow reminiscent of the sun; others make people feel cold and cool, such as blue, green and purple, and use these colors more in the cold drink hall. (2) color has a sense of excitement and composure. The excitement and calmness of color are caused by the stimulation of color to people. Red, orange and yellow are more exciting to people and give people excitement. These colours are often used in the layout of cake city or fast food restaurant. The excitement of cold colors such as blue, green and purple is weaker, and their excitement will decrease after seeing these colors. . (3) gorgeous colors and simple colors. The sense of elegance and simplicity of color is due to the difference between purity and brightness of color. Higher purity and brighter color give people a sense of gorgeousness, warm color also has a sense of gorgeousness; while low purity and lightness of the cold color system has a sense of simplicity; white, gold, silver has a sense of gorgeousness; black depends on the situation, sometimes with a sense of gorgeousness, sometimes with a sense of simplicity. (4) the sense of seriousness of color. The color sense of lightness is caused by the different lightness of color. High brightness color makes people feel light, usually in women's clothing stores or cosmetics stores with bright colors; while dark makes people feel heavy, generally used in gold and silver jewelry stores, home appliances city or automobile stores. (5) positive and negative colors. Warm colors such as red, orange and yellow are called positive colors; cold colors such as blue, green and purple are called negative colors. In terms of lightness, bright colors are positive colors and low brightness colors are negative. When white is used with other colors, it produces Yang Qi. Black makes people feel gloomy, while gray is neutral. (6) soft and hard colors. The sense of softness and hardness of color is caused by the lightness and purity of color. Generally speaking, the color with high lightness and low color has a soft feeling; while the color with low lightness and high color has a hard feeling; white and black have a hard feeling, and gray has a soft feeling. Apart from the above characteristics, color should also pay attention to the regionality and nationality of color in interior design, as well as personal preferences for color due to gender, personality, interest, occupation and environment.

\subsection{Interior Collocation}

(1) Wall color. Wall surface plays a dominant role in creating indoor atmosphere, warm color system can produce a happy and warm atmosphere; cold color system can cause cold feeling; bright neutral color can cause a clear and calm feeling. Generally, the color of the wall is slightly darker than that of the ceiling. It is better to use bright intermediate color instead of white or pure color. It is better to use some light color with low and high brightness. (2) Wall color. Wall groups are easily dirty, and their lightness can be reduced when they are designed. The color of the walls should not be too far from that of the walls. The shape lines of the walls are generally aligned with the windowsills. (3) skirting line color. The color of skirting lines usually uses a darker shade of wall or wall. (4) ground color. Floor generally uses the same color as the wall in the color of slightly different colors, generally using a stronger color. Wood color floors are also commonly used. (5) sky color. Smallpox can be used in white or near bright white color so that the indoor lighting effect is better. Smallpox should be more transparent than the wall when it is used in the same color as the wall. (6) furniture color. Furniture color can not be generalized, office desks, chairs, bookshelves and other functional furniture, in order to foil the white wall, furniture color can be darker, using 
non-stimulating color and low color. If the wall is warm color system, the furniture generally uses cold color system or neutral color; when the wall is cold color system or no color, the effect of using warm color system is better. (7) fitting accessories color. The color of doorframe and window frame should not be too contrasted with the color of the wall. Neutral color should be adopted. In order to unify the color of the whole room, all the color of the wall should be harmonized.

\section{The Use of Light in Indoor Environment.}

Light plays an important role in drying indoor environment and creating "artistic conception". The use of light in interior design includes the use of natural light and the use of artificial lighting. The use of natural light in indoor environment is mainly through two aspects: on the one hand, through the use of transparent glass roof, natural light is injected into the room through transparent glass roof; on the other hand, through modern scientific and technological means to control and adjust natural light, through the treatment of daylighting outlets to adjust the score of indoor natural light intensity. Cloth. The use of artificial lighting in indoor environment is manifold. From the purpose of lighting, it can be divided into practical lighting and decorative lighting. From the expression form of indoor light environment, it can be divided into "point" expression form, "face" expression form and "line" expression form. Mathematically speaking, a point is "only position but not size", but morphologically speaking, a smaller shape is also called a point, which can play the role of marking position in the space environment or making people focus their attention. In indoor environment, such as the light spot formed by the light on the ceiling at its interface, as long as it is small enough relative to the space where it is located, the light shape characterized by position can be regarded as the "spot" of light.

Lines are mathematically "locus of point movement". Morphologically, there are many kinds of lines with straight and curved lines. Some lines are visually intuitive, while the formation of some lines is the result of abstract thinking. In indoor light environment, the visual sense of line comes from the modeling factor of light source, that is, the movement track of light. For example, in indoor light environment design, light bands are often used on the axis of buildings to play a visual guiding role and enhance the sense of extension of indoor space. At the same time, this method can also strengthen the guiding role of human flow. The surface is the locus of the movement of the line, and the surface can also be obtained by enlarging the point or increasing the width of the line. In indoor environment, the perception of the surface comes from the two factors of the luminescent surface, which are affected by the smooth surface. The luminous surface is formed by light passing through diffuse material, such as luminous ceiling or light irradiated mantle. In indoor light environment, the receiving surface has more abundant expressions than the luminous mask. The diversity of interface and the uncertainty of illumination angle make the receiving surface have abundant expressions.

\section{Indoor Space Form Processing}

Different forms of space can cause different emotional responses, and the spatial meanings of metaphor are also different. The types of space can be divided into the following categories. Structural space, through the appreciation of the exposed part of the structure, to understand the structure of the concept level to create a beautiful environment of space formed by skills, can be called structural space. Open space, the degree of openness depends on whether there is a side interface, the extent of the side interface enclosure, the size of the opening and the control ability of opening and closing. Open space is often used as interior and exterior transitional space, which has certain mobility and high interestingness, and is the reflection of open psychology in the environment. Closed space is called closed space, which has strong isolation in vision, hearing and 
so on. Dynamic space, dynamic space guides people to observe things around them from the perspective of "moving", and brings people to a "fourth space" which combines space and time. Suspension space, indoor space in the vertical division of the suspension structure, the bottom interface of the upper space is not supported by walls or columns, but by suspension rods, or a small space erected by beams in the air, there is a sense of "suspension" and "floating". The motive of mobile space is not to regard space as a passive static existence, but as a vivid force. In space design, avoid isolated static volume combination, and pursue sports and continuous space. Static space, based on the law of life and activity of the combination of static and dynamic, and in order to satisfy people's psychological pursuit of alternation between static and dynamic, we should not neglect the study of static space while studying dynamic space.

Static space generally has the following characteristics: 1 . space is more limited and tends to be closed; 2 . multi-end space, where the sequence ends, is more private; 3. symmetrical space, apart from the new centripetal force, has less tendency to achieve a static beauty and balance; 4 . proportion and scale of space and furnishings. The degree is more harmonious; 5 . The tone is elegant and harmonious, the light is gentle and the decoration is concise; 6 . The line of sight changes peacefully, avoiding the factor of mandatory guiding line of sight. Virtual space, the scope of virtual space lacks a strong limit, it is based on the inspiration of some forms, relying on Association and Visual Gestalt to delimit space, this space is also called "psychological space". Shared space, in order to meet the needs of various complex social exchanges and life, has been created in environmental design. Shared space is often the center and transportation hub of large public buildings. It contains a variety of space elements and facilities, and is a comprehensive and flexible space. Mother-child space, mother-child space is the secondary restriction of space, which is a small space (sub-space) defined again in the original space (mother space) by physical or symbolic means. In the division of spatial level, besides the above, there are indefinite space, staggered space, concave space, convex space, subsidence space, platform space and so on.

\section{The Use of Interior Furnishings}

Indoor furnishings include many categories, including indoor furniture, indoor greening, indoor decorative fabrics, carpets, curtains, lamps, murals and so on. Indoor furniture is an important part of interior environment design. It is the main role that reflects the interior atmosphere and artistic effect. It forms an organic unity with the interior environment. Therefore, the creation of interior environment artistic conception can not be separated from the choice and organization of furniture. Indoor greening is another main aspect of artistic conception expression in interior space environment design. It mainly uses plant materials and combines common means and methods of gardens to organize and beautify interior space, coordinate the relationship between people and space environment, and further foil the interior atmosphere. In short, interior furnishings have a strong role in creating interior "artistic conception". Different furnishings can make people have different associations, arouse different emotions, and form different styles and artistic conceptions of interior space.

\section{Conclusions}

In the design of indoor space environment, water is used to arouse people's memory and attachment to nature and create beautiful associations, such as setting up streams and waterfalls indoors. The Renaissance Center in Detroit, USA, has built pillars and indoor greening from the water to integrate architecture with nature and evoke people's fond memories. Space is limited, but artistic conception is infinite. As a modern interior designer, we should create infinite situation in the limited space. Just as the window is near the canal, so does the book. A plain interior design will 
not have eternal aesthetic value, but an interior space with strong "artistic conception" beauty will leave a strong, interesting impression and will have an infinite vitality.

\section{References}

[1] Yang Qing. Creation of artistic conception in 3D indoor environment design [D]. Shandong University, 2012.

[2] Guo Chengbo. On the creation of artistic conception of indoor environment design [J]. art 100, 2006 (03): 160-162.

[3] Guo Liping. Creation of artistic conception in indoor environment [J]. Journal of Keshan Teachers College, 2003 (01): 94-96.

[4] Wu Yehong. Beyond Space: Creation of Artistic Conception in Interior Environment [J]. Interior Design and Decoration, 1990 (15): 9-11.

[5] Yang Zhengxin. Creating an Interior Environment Embodying the Connotation of Chinese Traditional Culture --Talking about the Creation of "Artistic Conception" in Interior Design [J]. Interior, 1988 (08): 10-11. 